\title{
XENODIAGNÓSTICO, HEMOCULTURA E TESTE DE LISE MEDIADA PELO COMPLEMENTO, COMO CRITÉRIOS DE SELEÇÃO DE PACIENTES CHAGÁSICOS CRÔNICOS PARA QUIMIOTERAPIA
}

\author{
Vera Lueia PEREIRA, Antonio Mareos de A. LEVY \& Elias BOAINAIN
}

\begin{abstract}
O tratamento etiológico da doença de Chagas é iniciado geralmente apenas quando se dispóe de um diagnóstico parasitológico positivo. Na tentativa de aumentar o número de candidatos assim selecionados para o tratamerito especifico, estudamos 36 pacientes chagásicos crônicos associando o xenodiagnóstico. a hemocultura e o teste de lise mediada pelo complemento. em duas séries sucessivas. intercaladas de um minimo de 60 dias. A sensibilidade do xenodiagnóstico e da hemocultura foi respectivamente de $30,5 \%$ e de $8,3 \%$ na primeira série e de $36,1 \%$ e de $19,4 \%$ nas duas séries.

Foram positivos, em pelo menos uma das duas provas, $17(47,2 \%)$ dos pacientes. Destes, entretanto, somente $9(53,0 \%$, mostraram teste de lise constantemente posi. tivo enquanto que em $5(29,4 \%)$ o teste foi negativo e $3(17,6 \%)$ apresentaram resulta dos ora positivos, ora negativos. Nos pacientes com provas parasitológicas negativas. $o$ teste de lise foi positivo em $4\left(15.8^{*}\right)$, negativo em $9(47.4 \%)$ e discordante em $6 ! 31,5 \%)$. Assim. o teste de lise mediada pelo complemento nào se constitue em bom metodo de triagem de candidatos ao tratamento. Apesar da baixa sensibilidade. as provas parasitológicas ainda constituem o instrumento mais seguro para o clínico.
\end{abstract}

UNITERMOS: Doença de Chagas: Testes para a seleção de pacientes cronicos ao tratamento específico.

\section{INTRODUÇÀO}

Um dos mais importantes critérios para a seleçào de pacientes chagásicos crônicos para o tratamento etiológico é a evidenciação de Trypanosoma cruzi na circulação sangüinea. O encontro do parasita antes do tratamento e o seu desaparecimento após o mesmo comprovam a eficiência da quimioterapia.

Em pacientes com infecçào chagásica aguda, a comprovação da parasitemia é feita por métodos diretos de relativa simplicidade, pois o numero de parasitas quase sempre é elevado. $\mathrm{Na}$ fase crònica da infecçāo, entretanto, a parasitemia geralmente é baixa e residual, tornando-se de difícil detecçảo. Neste caso, recorre-se a méto dos indiretos, como o xenodiagnóstico e a hemo. cultura, para a amplificaçāo do número de para sitas.

Em 1979, KRETTLI et al. ${ }^{10}$ introduziram

Trabalho realizado no Setor de Miocardiopatias do Instituto "Dante Pazzanese' de Cardiologia. Sä Paulo. SP. Brasil Endereço para correspondência: Vera Lucia Pereira. Instituto "Dante Pazzanese" do Cardiologia. Laboratório de Xenodiag nóstico. Av. Dr. Dante Pazzanese. 500. Caixa Postal 215. CEP 04012 Săo Paulo. SP. Brasil. 
PEREIRA. V. L.: LEVY. A. M. de A. \& BOAINAIN. E. - Xenodiagnóstico, hemocultura e teste de lise mediada pelo complemento. como critérios de seleçáo de pacientes chagasicos crónicos para quimioterapia. Rev. Inst. Med. trop. S. Paulo, 31(5): 301 307, 1989

o teste de lise mediada pelo complemento. Este teste poderia detectar anticorpos presentes em pacientes portadores de infecçáo ativa, sendo um marcador indireto da presença de tripomas tigotas.

Nosso interesse é selecionar um maior núme ro de pacientes chagásicos crónicos para as ten tativas de tratamento etiológico. O objetivo do presente estudo foi verificar se a lise mediada pelo complemento associada às provas parasito lógicas, bem como a realização mais frequente destes testes, poderiam contribuir para a eleva cáo do número de candidatos ao tratamento es pecífico

\section{MATERIAL E MÉTODOS}

\section{1 - Pacientes}

Foram selecionados trinta e seis pacientes chagásicos crônicos, com diagnóstico confirma do através das provas sorológicas reaçōes de fixação de complemento, hemaglutinação indi reta com 2-mercaptoetanol, aglutinaçāo direta com 2 mercaptoetanol e imunofluorescencia in direta anti-IgG). Os pacientes encontravam-se na forma indeterminada da doença, diagnosti cados através de exames clínicos, eletrocardio gráficos e radiológicos. Todos eram do sexo mas culino, com idade nào superior a 40 anos e com domicilio na Grande São Paulo. Cada paciente foi submetido a duas séries de testes, que com preenderam o xenodiagnóstico, a hemocultura e a lise mediada pelo complemento. As duas séries de testes foram realizadas em ocasióes dife rentes, com intervalo minimo de 60 dias.

\section{2-Xenodiagnóstico}

O teste foi realizado com quatro caixas, idea lizadas por um de nós' ${ }^{1}$ contendo cada caixa 10 ninfas de Triatoma infestans, aplicadas nos bra cos e antebraços do paciente. Este processo foi repetido três vezes, com intervalo médio de 10 dias entre as aplicaçóes. Após 30 dias, foi efetua da leitura por observaçāo em microscópio de fase, do conteúdo intestinal obtido por compres são abdominal dos triatomineos. Decorridos mais 30 dias, foi feita nova leitura, desta vez do material obtido através da dissecação dos triato mineos

\section{3 - Hemocultura}

Foram coletados de 20 a $30 \mathrm{ml}$ de sangue venoso heparinizado de cada paciente. A técnica foi realizada conforme preconizado por CHIARI et al. $(1979)^{7}$. Após a centrifugaçāo inicial a 1500 g durante 30 minutos, o plasma foi retirado e as hemácias lavadas com meio LIT (Liver Infu sion Tryptose) por nova centrifugaça a $1500 \mathrm{~g}$ durante 15 minutos. Seguiu se, então, a semea dura em meio LIT (seis tubos). As leituras foram realizadas por observaçāo microscópica de gotas do meio, 15. 30 e 45 dias após a semeadura. Decorridos 60 dias, uma nova leitura foi realizada. quando, então, os tubos foram novamente cen trifugados a $1500 \mathrm{~g}$ durante 15 minutos, sendo o sobrenadante desprezado e a leitura realizada na papa de hemácias.

\section{4-Lise mediada pelo complemento}

Os soros recém obtidos foram congelados a $20^{\prime \prime} \mathrm{C}$. Para o teste foram descongelados, inativa dos e diluidos a 1:2 e 1:4. A técnica foi realizada conforme já descrito (LEVY et al., 1988) $)^{13}$. Fo ram utilizados os seguintes controles: 1 - "complemento" - para verificar se os camundongos foram adequadamente suprimidos e seus anticorpos náo ficaram aderidos à membrana dos tripomastigotas, provocando resultados mais al tos. Este mesmo controle permite verificar se o complemento humano utilizado na reação náo provoca reaçós inespecíficas, tal como a agluti nação e/ou morte dos parasitas independente do fenomeno da lise; 2 - negativo - soros de pacientes cardiopatas nāo chagásicos. Foi esta belecido que neste controle nāo deveria ocorrer mais que $20 \%$ de lise dos tripomastigotas, embo ra a média tenha sido de cerca de $14 \%$ de lise: 3 - positivo - soros de pacientes chagásicos que em reaçóes anteriores apresentaram lise aci ma de $41 \%$ dos tripomastigotas. Estes soros fo ram aliquotados após a reação e congelados a $-20 \mathrm{C}$, devendo a cada reação repetir o resultado obtido na primeira vez, com variaçáo de $\pm 8 \%$ : 4 - inespecifico - os soros de pacientes náo chagásicos foram adicionados a tripomastigo tas, na diluiçāo $1: 3$, para verificar se os parasitas não sofreram lise inespecífica após o periodo de incubação. Neste controle não foi adicionado complemento ativo e foi estabelecido que deveria dar um resultado tal que multiplicado por 
PEREIRA, V. L.: LEVY, A. M. de A. \& BOAINAIN, E. - Xenodiagnóstico, hemocultura e teste de lise mediada pelo complemento, como critérios de seleçáo de pacientes chagásicos crônicos para quimioterapia. Rev. Inst. Med. trop. S. Paulo, 31(5): 301 307, 1989 .

três, fornecesse o número inicial de tripomastigotas, com variaçào de até $15 \%$.

\section{RESULTADOS}

Nos 36 pacientes submetidos ao xenodiag nóstico è hemocultura obtivemos os seguintes resultados: $11(30,5 \%)$ pacientes foram positivos no primeiro teste de xenodiagnóstico e $8(22,2 \%)$ no segundo, sendo que $6(16,6 \%)$ apresentaram resultados positivos tanto no primeiro quanto no segundo teste. Treze $(36,1 \%)$ pacientes mos traram resultados positivos em pelo menos um dos testes. (Quadro 1).

Em relaçāo à hemocultura, $3(8,3 \%)$ pacientes mostraram resultados positivos na primeira amostra e $6(16,6 \%)$ na segunda, sendo que 2
$(5.5 \%)$ foram positivos em ambas amostras. Sete $(19,4 \%)$ pacientes apresentaram parasitas em pe lo menos uma das amostras. (Quadro 2 ).

Com a utilizaçāo de ambas provas parasitológicas, em duas amostras como explicado anteriormente, apenas 3 pacientes foram positivos em ambos os testes e $17(47,2 \%)$ foram positivos em pelo menos uma das provas ou amostras. (Quadro 3).

Entre os 17 pacientes com provas parasito lógicas positivas, $9(53,0 \%)$ apresentaram níveis de anticorpos líticos considerados positivos, 5 $(29,4 \%)$ mostraram niveis de anticorpos conside rados negativos e $3(17,6 \%)$ apresentaram resultados discordantes, ora positivos ora negativos, dependendo da amostra. (Figura 1).

\section{QUADRO 1}

Resultados do xenodiagnóstico nos casos em estudo

\begin{tabular}{cccccc}
\hline \multirow{3}{*}{ Pacientes } & \multicolumn{5}{c}{ Xenodiagnósticos } \\
\cline { 2 - 6 } & \multicolumn{2}{c}{ positivos } & & negativos \\
\cline { 2 - 6 } & 1a amostra & 2 a amostra & ambas as amostras & Total \\
\hline \multirow{2}{*}{36} & 11 & 8 & 6 & 13 & 23 \\
& $(30,5 \%)$ & $(22,2 \%)$ & $(16,6 \%)$ & $(36,1 \%)$ & $(63,9 \%)$ \\
\hline
\end{tabular}

QUADRO 2

Resultados da hemocultura nos casos em estudo

\begin{tabular}{cccccc}
\hline \multirow{3}{*}{ Pacientes } & \multicolumn{5}{c}{ Hemoculturas } \\
\cline { 2 - 6 } & \multicolumn{2}{c}{ positivas } & \multicolumn{3}{c}{ negativas } \\
\cline { 2 - 6 } 36 & 3 & 6 & 2 & 7 & \\
\hline \multirow{2}{*}{36} & $(8,3 \%)$ & $(16,6 \%)$ & $(5,5 \%)$ & $(19,4 \%)$ & $(80,6 \%)$ \\
\hline
\end{tabular}

QUADRO 3

Resultados de ambos os testes parasitológicos nos casos em estudo

\begin{tabular}{cccccc}
\hline \multirow{2}{*}{ Pacientes } & \multicolumn{2}{c}{ casos positivos } & \multicolumn{2}{c}{ casos negativos } \\
\cline { 2 - 6 } & xenodiagnóstico & hemocultura & ambos os testes & Total & \\
\hline \multirow{2}{*}{36} & 13 & 7 & 3 & 17 & 19 \\
& $(36,1 \%)$ & $(19,4 \%)$ & $(8,3 \%)$ & $(47,2 \%)$ & $(52,8 \%)$ \\
\hline
\end{tabular}


PEREIRA, V. L.: LEVY, A. M. de A. \& BOAINAIN, E. - Xenodiagnóstico, hemocultura e teste de lise mediada pelo complemento, como critérios de seleçáo de pacientes chagásicos crónicos para quimioterapia. Rev. Inst. Med. trop. S. Paulo, $31(5): 301-307.1989$

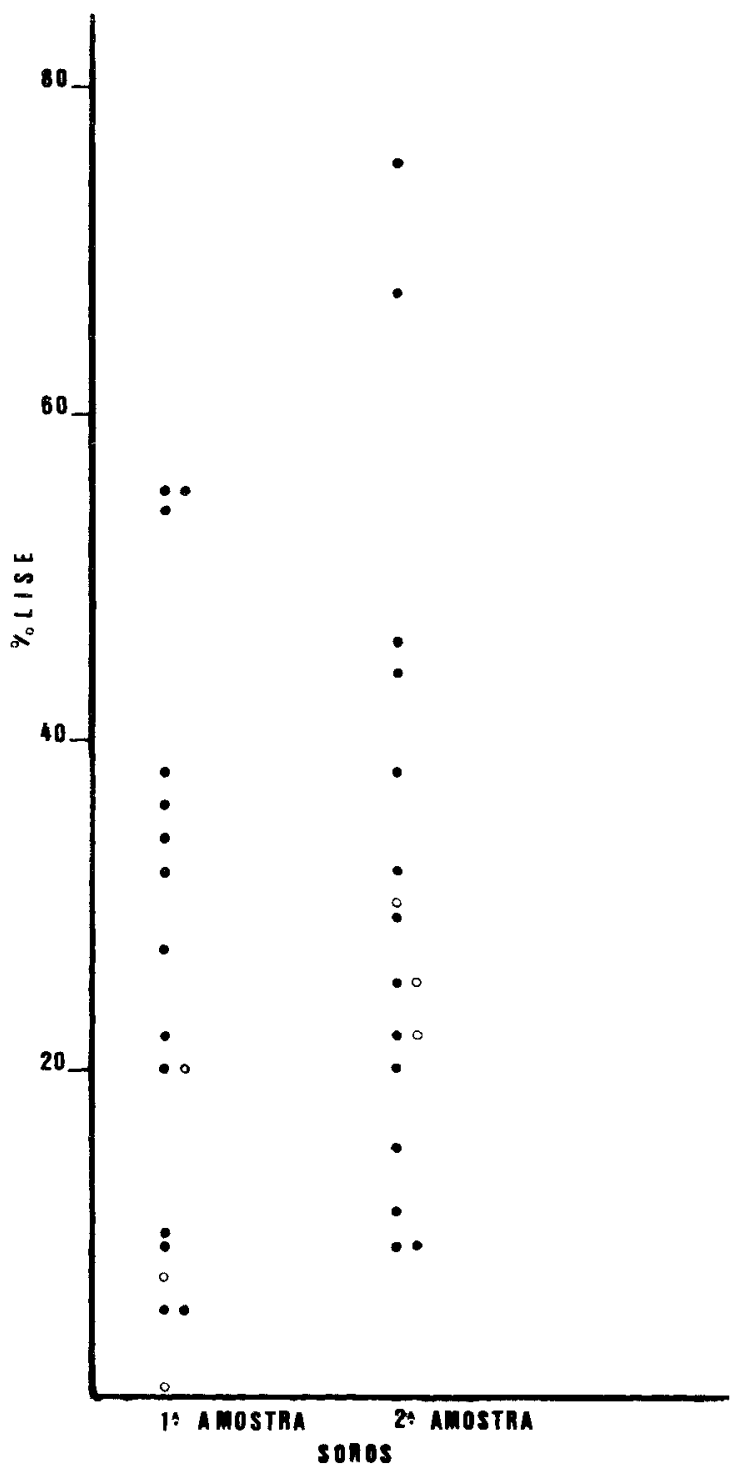

- resulados concordantes em ambas amostras.

- = itsulados discorrantes.

Fig. 1 -... Distribuiçáo dos resultados de lise nas duas amostras ce soro dos pacientes com provas parasitologicas positivas.

Entre os 19 pacientes com provas parasito lógicas negativas, $9(47,4 \%)$ apresentaram niveis de anticorpos líticos negativos, $4(15,8 \%)$ apresentaram niveis positivos de lise e $6(31,5 \%)$ mos traram resultados discordantes, ora positivos, ora negativos. (Figura 2).

\section{DISCUSSÃO}

Desde a sua in troduçāo por BRUMPT $(1912)^{4}$

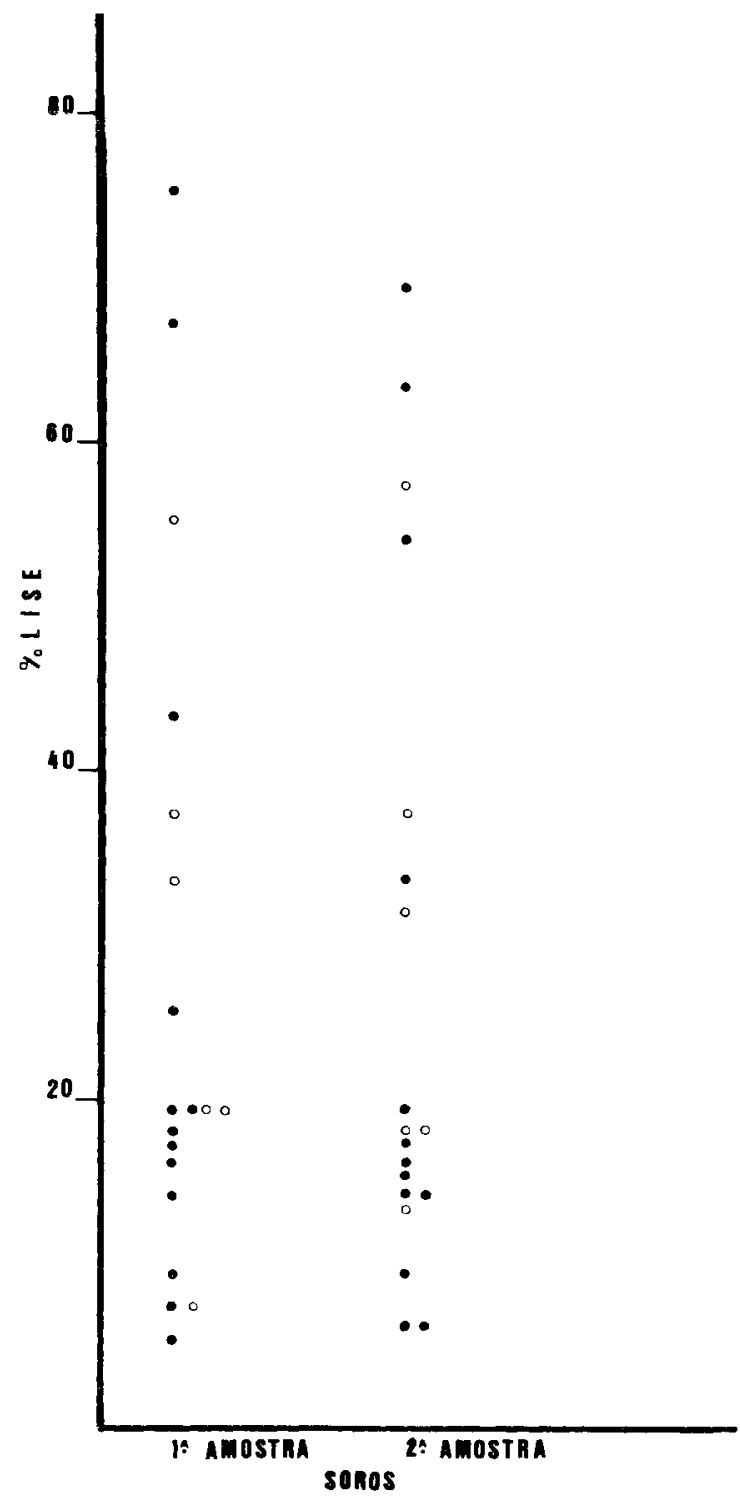

- - resultados concordantes em ambas amostras.

$0=$ resultados discordantes.

Fig 2 - Distribuiçāo dos resultados de lise nas duas amostras de soros de pacientes com provas parasitologicas negativas.

numerosas pesquisas envolvem o xenodiagnóstico, visando aumentar seu indice de positividade. CERISOLA et al. $(1974)^{6}$ demonstraram que a utilização de 40 ninfas de 3 estágio de $\mathbf{T}$. infestans oferecia $53 \%$ de testes positivos e que um maior número de insetos nāo aumentava proporcionalmente o indice de positividade. CASTRO et al. $(1983)^{5}$, trabalhando com pacientes de zona endêmica, demonstraram que 
PEREIRA, V. L.: LEVY, A. M. de A. \& BOAINAIN, E. - Xenodiagnostico, hemocultura e teste de lise mediada pelo complemento, como critérios de seleçāo de pacientes chagásicos crónicos para quimioterapia Rev. Inst. Med. trop. S. Paulo, 31(5): 301-307. 1989

a repetição do xenodiagnóstico, especialmente, nos individuos de baixa parasitemia, mostrava uma elevaçāo significativa da positividade. BRONFEN et al. $(1981)^{3}$ e SZUMLEWICZ et al. $(1987)^{16}$ chamaram atenção para o uso de vetores de significância epidemiológica na região a ser realizado o xenodiagnóstico. A dissecaçāo dos insetos utilizados no xenodiagnóstico, após a constatação negativa do parasita nas fezes do triatomíneo foi sugerida por BRONFEN.

Nossa experiência em laboratório (BOAI NAIN, 1979) $)^{1}$, além de confirmar os dados obti. dos por CERISOLA ${ }^{6}$, mostrou que determinadas espécies vetoras como Triatoma vitticeps e Dipetalogaster maximus não oferecem vantagens significativas sobre o Triatoma infestans na uti lizaçāo para o xenodiagnóstico. A primeira mostrou-se menos suscetível ao T. cruzi e a segunda ofereceu um maior número de reações de hipersensibilidade nos pacientes (dados não publicados). Diante de tais dados, justifica-se a utiliza ção de $\mathbf{T}$. infestans no xenodiagnóstico. Esta espécie, além de possuir um alto grau de domiciliaçāo, foi a que melhor se adaptou em nosso laboratório, possuindo alto grau de antropofilia e boa suscetibilidade ao T. cruzi.

A hemocultura, assim como o xenodiagnós tico, já foi extensivamente estudada, sempre com o objetivo de aumentar a sensibilidade da técnica. Vários meios de cultura para o crescimento do T. cruzi foram desenvolvidos e estudados, visando um rápido aumento do número de protozoários eventualmente presentes (LOPETEGUI et al., 1982, ${ }^{14}$. Outros fatores importantes e inerentes à técnica foram também avaliados, como: o volume de sangue a ser utilizado (JAN KEVICIUS et al., 1979$)^{9}$, a remoção do plasma e a lavagem das hemácias (CHIARI et al., 1979) a velocidade de centrifugaçāo (SOUZA et al., $1985)^{15}$ e os intervalos de leituras. Todos estes fatores sâo de extrema importância e podem interferir nos resultados obtidos (CHIARI, 1988) ${ }^{8}$.

Os pacientes chagásicos crônicos deste estudo constituíram-se em grupo homogêneo, no que diz respeito à idade, sexo, forma clínica e tempo de domiciliaçāo em zona urbana. A positividade do xenodiagnóstico, nestes pacientes, na primeira bateria de testes foi de $30,6 \%$, na segunda de $22,2 \%$ e em ambos testes de $36,1 \%$ confirmando a variaçāo da sensibilidade do xenodiagnóstico em testes reiteradamente praticados. Estes dados, diferem de outros anteriormente observa dos por nós (BOAINAIN, $1979^{1}$ e BOAINAIN et al., $\left.1979^{2}\right)$ nos quais se obteve $43 \%$ de sensibi lidade.

As mesmas observações foram notadas em relaçāo à hemocultura que teve positividade de $19,4 \%$ nas duas amostras, inferior, portanto, à do xenodiagnóstico. Na primeira bateria foi en contrada positividade de $8,3 \%$ e na segunda de $16,7 \%$.

A presença de T. cruzi na circulação sangüí nea desperta a presença de anticorpos especí ficos que são capazes de provocar a lise de formas tripomastigotas na presença do complemento. Desta forma, tais anticorpos protetores só estariam presentes na infecçào ativa. KRETTLI et al. (1982 11 e $\left.1984^{12}\right)$ mostraram que pacientes chagásicos crônicos não tratados apresentavam altos niveis de anticorpos líticos e que tais anticorpos poderiam ser evidenciados pela lise mediada pelo complemento ou pela imunofluorescência de membrana. No presente estudo, dos 17 pacientes com provas parasitológicas positivas, $9(53,0 \%)$ também apresentaram resultados de lise positivos, $(\overline{\mathrm{x}}=36 \%$ de lise dos tripomastigotas). Foi observado que $5(29,4 \%)$ pacientes com provas parasitológicas positivas apresen taram resultados de lise negativos. A média de lise dos tripomastigotas nestes pacientes foi de $14 \%$, semelhante à do grupo controle negativo. Quatro pacientes $(21,0 \%)$ com provas parasitológicas negativas apresentaram niveis de anticorpos líticos considerados positivos. A manu tençāo de resultados positivos na lise poderia sugerir uma futura prova parasitológica positiva.

Deve ser observado que a lise mediada pelo complemento apresentou resultados discordantes, ora negativos, ora positivos, tanto em pacientes com provas parasitológicas negativas $(31,5 \%)$ quanto em pacientes com provas parasitológicas positivas $(\mathbf{1 7 , 6 \% )}$. Nenhuma relação foi observada entre esses resultados da lise mediada pelo complemento e das provas parasitológicas, podendo um resultado de lise corresponder ou nāo a uma prova parasitológica positiva. 
PEREIRA, V. L.: LEVY, A. M. de A. \& BOAINAIN, E. - Xenodiagnóstico. hemocultura e teste de lise mediada pelo complemento. como critérios de seleção de pacientes chagásicos crónicos para quimioterapia. Rev. Inst. Med. trop. S. Paulo, 31(5): $301307,1989$.

Sabe-se que a parasitemia em pacientes cha gásicos crónicos é quase sempre muito baixa, residual e detectada com grande dificuldade através do xenodiagnóstico, da hemocultura e mesmo pela lise mediada pelo complemento. Mesmo pela associação destes métodos e/ou por exames seriados nāo se ultrapassa um índice de 50\% de positividade (CHIARI, 1988). Conside rando se pelo menos uma das provas ou amostras positivas, a sensibilidade das provas parasi tológicas foi de $47,2 \%$. Ao final deste estudo, os pacientes positivos em qualquer prova parasitológica foram encaminhados ao tratamento tripa nosomicida.

O presente estudo sugere que a lise mediada pelo complemento não se constitui em bom método para a triagem de pacientes candidatos ao tratamento, pela grande variabilidade dos resultados obtidos. A comprovação parasitológica da infecção crônica, através das provas parasitológicas, especialmente o xenodiagnóstico, em. bora insatisfatória para a seleção de pacientes ao tratamento, constitui-se, até o presente mo mento, no instrumento mais seguro para o clíni co, especialmente quando reiteradamente praticado.

\section{SUMMARY}

\section{Xenodiagnosis, hemoculture and complement mediated lysis tests as criteria for selection of chronic chagasic patients for chemotherapy}

Normally specific treatment of chronic Chagas' disease begins only after a positive parasitological diagnosis has been established. Xenodiagnosis, hemoculture and complement mediated lysis were associated, and repeated, as an attempt to increase the number of selected candidates for specific treatment. Thirty six chronic chagasic patients were submitted to two series of the above tests, with a minimal interval of 60 days. In the first series of tests sensitivity of xenodiagnosis and hemoculture were $30.5 \%$ and $8.3 \%$ respectively. Processing of a second sample increased sensitivity to $36.1 \%$ (xenodiagnosis) and $19.4 \%$ (hemoculture); $47.2 \%$ were shown to be positive by at least one of these tests. From the positive cases, $29.4 \%$ were consistently negative in the complement mediated lysis test, and $17.6 \%$ exhibited discordant results, positive on one occasion and negative on the other. Among patients with negative parasitological tests. $47.4 \%$ had negative complement mediated lysis tests, $31.5 \%$ exhibited discordant results and $15.8 \%$ were positive.

We conclude that complement mediated lysis test is not a method of choice in the selection of candidates for specific treatment of Chagas. disease in view of the observed variability of results. At this moment, parasitological tests, in spite of a low sensitivity, are a safer tool for the clinician.

\section{AGRADECIMENTOS}

À Bióloga Ediliz Maria Ramos de Amorim pela participação ativa no presente estudo.

À Técnica de Laboratório Vera Lucia Fioratti pela realização das provas sorológicas.

REFERENCIAS BIBLIOGRAFICAS

1. BOAINAIN, E. - Tratamento etiologico da doença de Chagas na fase cronica. Rev. goiana Med., 25: 1-60, 1979.

2. BOAINAIN, E.: PEREIRA, V. L SAVASTANO, L. B M \& RAMOS, M. C. - Avaliaçào da sensibilidade do xeno diagnóstico. In: CONGRESSO INTERNACIONAL SO BRE DOENCA DE CHAGAS, Rio de Janeiro, 1979. Anais. p. 153 .

3. BRONFEN. E.: DIAS. J. C. P. \& ROCHA, F S. A. - Early examination of xenodiagnosis as an alternative to impro. ve efficiency of this method on chronical Chagas disease. In: REUNIĀO ANUAL SOBRE PESQUISA BASICA EM DOENCA DE CHAGAS, Caxambú, 1981. Programa e resumos. p. 58 . res. n.' 60 .

4. BRUMPT, E. \& SILVA, P. - Existence du Schyzotrypanum cruzi Chagas 1909 , à Bahia (Matta de Sào Joào

Biologic du Conorhinus megistus. Bull. Soc. Path. rxot., 5: 2226.1912 .

5. CASTRO.C.N : ALVES, M. T \& MACEDO.V.O. - Impor táncia de repetição de xenodiagnóstico para avaliaça da parasitemia na fase crónica da doença de Chagas. Rev. Soc. bras. Med. trop., 16: $98.103,1983$.

6. CERISOLA, J.A.; ROHEDDER, R.W.; SEGURA, E.; DEL PRADO, C. E.; ALVAREZ, M. \& DE MARTINI. G. W -.. El xenodiagnostico. Buenos Aires, Instituto Nacional de Diagnostico e Investigación de lá Enfermedad de Cha gas "Dr. Mario Fatala Chaben", 1974. 112 p. rMimeogra fadol. 
PEREIRA, V. L.: LEVy. A. M. de A. \& BOAINAIN, E. - Xenodiagnóstico, hemocultura e teste de lise mediada pelo complemento, como critérios de seleção de pacientes chagásicos crónicos para quimioterapia. Rev. Inst. Med. trop. S. Paulo, $31(5): 301307,1989$.

7. CHIARI, E.: DiAs. J. C. P.: LANA. M. \& CHIARI, C. A - Hemocultures for the parasitological diagnosis of hu man Chagas' disease in the chronic phase. In: CONGRES SO INTERNACIONAL SOBRE DOENCA DE CHAGAS Rio de Janeiro, 1979. Anais. p. N1 N5.

8. CHIARI, E. - Aspectos práticos do diagnóstico parasito lógico em doença de Chagas. In: REUNIĀO DE PESQUI SA APLICADA EM DOENÇA DE CHAGAS. 5., Araxá MG, 1988. Programa e resumos. p. 10.

9. JANKEVICIUS, S. I : MAEJIMA, H. K : JANKEVICIÚS J. V.; SANTOS. L.: MARTINEZ. M. M. R. \& MAEDA. L. A. - Trypanosoma cruzi hemoculture in blood banks In: CONGRESSO INTERNACIONAL SOBRE DOENÇA DE CHAGAS, Rio de Janeiro. 1979. Anais. p. 150.

10. KRETTLI, A. U.; WEISZ CARRINGTON, P. \& NUS SENZWEIG. R. S. - Membrane bound antibodies to bloodstrain. Trypanosoma cruzi in mice - Strain diffe rences in susceptibility to complement mediated lysis. Clin. exp. Immunol., 37: 416-423, 1979.

11. KRETTLI, A. U.: CANCADO, J.R. \& BRENER, Z, - Ef fect of specific chemotherapy on the levels of lytic antibo dies in Chagas disease. Trans. roy. Soc. trop. Med. Hyg., 76: $333-340,1982$.

12. KRETTLI, A, U.: CANÇADO, J.R. \&BRENER, Z - Crite rion of cure of human Chagas disease after specific chemo therapy: recent advances. Mem. Inst. Oswaldo Cruz, 79 $157-164.1984$.

13. LEVY, A. M. A.: PEREIRA. V. L. \& BOAINAIN. E. Avaliaçào da técnica de lise mediada por complemento em pacientes chagásicos cónicos tratados com drogas tripanosomicidas. Rev. Inst. Med. trop. S. Paulo, 30: 32.39 1988.

14. LOPETEGUI, R. \& SOSA MIATELLO, C. - Desarrollo y diferenciación de Trypanosoma cruzi in medios liquidos libres de celulas. Rev. Iat.-amer. Microbiol., 24: 125133 1982 .

15. SOUZA, H. A. \& LUQUeTTI. A. O. - Hemocultura na fase crônica da doença de Chagas. Padronizaçào da forca centrifuga do sangue heparinizado. In: REUNIĀO ANUAL SOBRE PESQUISA APLICADA EM DOENCA DE CHA GAS, 4.. Araxá, MG, 1987. Programa e resumos. p. 48. (Rev. Soc. bras. Med. trop., 20 (supl. 2 ₹; 48,1987 ).

16. SZUMLEWICZ. A. P. \& MULLER, C. A. - Studies in search of a suitable experimental insect model for xeno diagnosis of host with Chagas disease 2 - Attempts to upgrade the reliabelity and the efficacy of xenodiagnosis in chronic Chagas' disease. Mem. Inst. Oswaldo Cruz, 82: 259-272, 1987

Recebido para publicaçāo em 1331989 